\title{
OS DESAFIOS DA INSERÇÃO DE DEFICIENTES NO MERCADO DE TRABALHO
}

\section{ARTIGO DE REVISÃO}

PINTO, Silvana Regina ${ }^{1}$

SCATOLIN, Henrique Guilherme ${ }^{2}$

PINTO, Silvana Regina. SCATOLIN, Henrique Guilherme. Os desafios da inserção de deficientes no Mercado de Trabalho. Revista Científica Multidisciplinar Núcleo do Conhecimento. Ano 05, Ed. 06, Vol. 02, pp. 131-148. Junho de 2020. ISSN: 24480959, Link de

acesso: https://www.nucleodoconhecimento.com.br/psicologia/insercao-dedeficientes

\section{RESUMO}

Esta pesquisa tem por objetivo destacar a inserção das pessoas com deficiência no mercado de trabalho, apontando as dificuldades em sua inserção, acessibilidade e também suas diversas colocações no mesmo. Diante deste tema, este estudo tem como questão disparadora: As empresas estão suficientemente preparadas para acolher as pessoas com deficiência, dando-Ihes oportunidades de crescimento? Tal questão será discutida nesta pesquisa através de uma revisão bibliográfica, baseada nos pressupostos da Psicologia Social, a fim de que reflitamos sobre esta, já que cada vez mais, o governo tem desenvolvido novas leis e decretos que concedem direitos a essas pessoas, permitindo que elas tenham uma vida profissional semelhante à de qualquer outro cidadão, porém, ainda há muitas situações que impedem essas pessoas de viverem de tal forma, impedindo-as de mostrarem seus talentos e

1 Psicóloga pela Unifaj com pós-graduação em Psicologia Organizacional e do Trabalho pela FHO - Uniararas.

2 Doutor em Psicologia. 
habilidades, bem como desenvolver seu potencial. Assim sendo, conclui-se que é fundamental que busquemos entender e conhecer cada vez mais sobre as pessoas com deficiência e o cenário que elas enfrentam na sociedade, sobretudo nos meios profissionais, investindo nesta área, possibilitando que cada pessoa possa demonstrar suas capacidades e desenvolver suas habilidades nos meios profissionais, sendo verdadeiramente reconhecidas neste contexto.

Palavras-Chave: Inserção, pessoa com deficiência, acessibilidade, qualificação.

\section{INTRODUÇÃO}

A inserção das pessoas com deficiência no mercado de trabalho é de suma importância, principalmente no que se refere aos desafios para a ocorrência da mesma. Essas dificuldades são diversas, desde o tipo de deficiência, aceitação, motivação, preconceito, qualificação e até mesmo o fato de as empresas aderirem às cotas e, consequentemente, abrirem vagas, bem como a adequação da mesma para receber esses novos funcionários.

Um dos temas de direitos humanos voltados para a pessoa com deficiência parte do princípio que todo ser humano tem direito de dispor das condições necessárias para o desenvolvimento de suas habilidades, alcançando suas aspirações livres de qualquer tipo de discriminação.

De acordo com Diniz (2009), reconhecia-se a deficiência como uma experiência que levava à pressão sofrida pelas pessoas com impedimentos. Esse pensamento foi mudando com o passar do tempo, quando se criou um novo conceito com o intuito da valorização humana, independentemente da sua condição física ou espiritual, o que desfavorece a ideia de deficiência como impedimento.

O preconceito ainda existente na sociedade não é um fenômeno recente. Historicamente, essa população recebeu diversos tipos de tratamentos. Nos tempos antigos, os registros evidenciavam que alguns povos eram oprimidos, abandonados, 
exterminados e outros até mesmo segredados do convívio social. Recentemente, essas pessoas passaram a ser aceitas como sujeitos de direitos.

E no que se refere aos direitos trabalhistas, as pessoas com deficiência e acidentadas são amparadas pela Constituição Brasileira - Lei 8213/91. Amparadas na reserva de cargos e tendo a proibição de qualquer discriminação à remuneração e critério de admissão a seus favores. A mesma lei regulamenta porcentual nos postos de trabalho de acordo com o número de empregados das empresas. O direito ao trabalho do deficiente também é assegurado pelo decreto 3298/99.

Nos dados coletados pelo Instituto Brasileiro de Geografia e Estatística - IBGE, no censo demográfico de 2010, 45.606 .048 de brasileiros, $23,9 \%$ da população total, têm algum tipo de deficiência - visual, auditiva, motora e mental ou intelectual. 25.800.681 $(26,5 \%)$ são mulheres e 19.805.367 (21,2\%) são homens. 38.473 .702 pessoas vivem em áreas urbanas e 7.132.347 em áreas rurais. Esses dados dão subsídios para a necessidade de artigos que discutam questões que envolvam a deficiência em todos os âmbitos. Porém, a partir da possibilidade de ter acesso a essa população por meio de um trabalho em uma instituição, na qual busca inserir a Pessoa com Deficiência (PcD) no mercado de trabalho e esbarrando nos desafios para essa inserção, surge uma grande indagação que nos faz refletir e pesquisar sobre o tema. Quando pensamos em oportunidades para todos, observamos que na prática, muitas vezes, a lei se torna tímida. Diante de tantas dificuldades, cria-se a Lei das Cotas na tentativa de garantia de direitos.

A lei no 8213/91, de 24 de julho de 1991, conhecida como "LEI DE COTAS", tem como uma das várias propostas a inclusão social de deficientes no mercado de trabalho, com grande empenho no sentido de incentivo à inclusão dos deficientes trabalhadores, visando os benefícios do empregado e empregador, pois existem problemas, como a qualificação profissional, infraestruturas e preconceito, entre outros.

Segundo Sassaki (2003), os deficientes têm os mesmos direitos e deveres que as demais pessoas. Com o passar do tempo, receberam siglas diferentes para a sua 
definição. Inicialmente chamados de PPD (Pessoas Portadora de Deficiência), por solicitação dos próprios deficientes, tiveram sua denominação alterada para PNE (Pessoa com Necessidades Especiais) e, atualmente tem a nomenclatura correta: PCD (Pessoa com Deficiência).

Conforme dados coletados da AVAPE - Associação para Valorização de Pessoas com Deficiência, a qualificação e a acessibilidade podem ser ferramentas no auxílio à inclusão. A implantação de programas assistenciais e atendimento especializado ao deficiente vêm contribuindo significativamente e de forma produtiva com o uso de pessoas inclusas na sociedade, fomentando a geração de renda e de trabalho, minimizando os dados apresentados na estatística brasileira sobre exclusão social.

Assim, o objetivo principal desta pesquisa é compreender melhor a questão da pessoa com deficiência no mercado de trabalho, no que diz respeito à acessibilidade fornecida pelas empresas e também à qualificação que as mesmas podem oferecer a essas pessoas, possibilitando repensar as práticas, a aceitação, a motivação, o que essas empresas pensam e o quanto há de investimento para a capacitação dessas pessoas para ocupar as cotas obrigatórias por lei.

Deste modo, justifica-se a importância de desenvolver trabalhos direcionados a este assunto, principalmente quando pensamos nas dificuldades da inserção no mercado de trabalho, tanto quanto no aumento de pessoas portadoras de deficiências nesses últimos anos.

Para melhor compreensão do tema proposto, este trabalho trará como foco a questão da acessibilidade e também da qualificação profissional. Desta forma, a partir da pesquisa bibliográfica de vários artigos, livros e leis, retirados de sites universitários confiáveis, com intuito de pensar e repensar as dificuldades enfrentadas pela pessoa com deficiência no que diz respeito à sua inserção e qualificação no mercado de trabalho, esta pesquisa busca a diminuição do preconceito e o favorecimento de um desenvolvimento saudável, bem como da potencialidade de cada indivíduo. 


\section{FUNDAMENTAÇÃO TEÓRICA}

Quando pensamos na inserção de pessoas com deficiência no mercado de trabalho, percebemos que ainda há longos caminhos que devem ser percorridos para que ela aconteça de um modo que favoreça a pessoa e o dono da empresa que a contrata. Percebemos também que o preconceito ainda é uma barreira a ser derrubada, assim como a falta de atenção às PCDs. A queda dessas barreiras que impedem a inserção dessas pessoas é fundamental quando pensamos em uma boa acessibilidade e qualificação profissionais.

Porém, essas barreiras e dificuldades de inserção e inclusão não são atuais. Desde os primórdios, já havia dificuldades para que uma pessoa com deficiência pudesse ser aceita em sociedade e também no mercado profissional. De acordo com Almeida (2014), no século XIX, quando o regime monárquico ainda predominava no Brasil, começaram a surgir os primeiros institutos que buscassem um olhar diferente a essas pessoas.

Na época foram inaugurados o Hospício de Pedro II, o Instituto dos Meninos Cegos e também o Instituto dos Surdos Mudos. Podemos então notar que, embora começassem a surgir as primeiras atenções às PCDs, essas eram somente para cegos e surdos mudos, não englobando, portanto, outros tipos de deficiências.

Ainda segundo a autora, a mudança começou a acontecer com a queda do regime monárquico, quando os institutos tiveram seus nomes modificados. Proporcionadas pela República, a sociedade civil se organizou, criando novas iniciativas voltadas às pessoas com deficiência. Foi então que surgiram instituições como, a APAE, FENAPAES, ABBR, entre outras tantas que passaram a olhar não somente pessoas deficientes visuais, auditivas e de fala, mas também outras deficiências existentes, permitindo assim, que essas pessoas obtivessem uma melhor atenção e pudessem ser mais aceitas e inclusas na sociedade.

Figueira (2008) afirma que foi com a Constituição Cidadã que a proteção social das pessoas com deficiência passou a integrar às normas constitucionais no Brasil. Antes 
que isso ocorresse, era somente na esfera do assistencialismo, das práticas curativas e dos cuidados familiares que se situavam as políticas e ações de proteção a essas pessoas, isso quando o tratamento não ficava no âmbito do abandono e do enclausuramento.

Conforme mencionado pelo autor, as ações assistencialistas eram o único meio de subsistência da população com deficiência, que eram atendidas pela caridade.

Em 1981, foi reconhecida pela Organização das Nações Unidas (ONU) a responsabilidade dos governos por garantir direitos iguais às pessoas com deficiência num marco democrático de reajustes sociais, estruturas e políticos para contratar o tema na esfera dos direitos humanos (DINIZ; FIGUEIRA, 2008, p. 40).

$\mathrm{Na}$ Revolução Industrial, o modelo de proteção capitalista passou a valorizar o potencial produtivo do público. Houve então a necessidade de estruturação de sistemas nacionais de ensino e escolarização para a população potencialmente produtiva da época, o que chamou de "momento da educação" (ARANHA; 1995, p. 70)

Visando o aumento da mão-de-obra para a produção, surgia então a necessidade da formação de cidadãos produtivos. Foi então que surge uma maior responsabilidade pública pelas necessidades da PCD, pois eles começam naquele momento, a ser vistos como potencialmente capazes de executar tarefas industriais. Desse modo, percebemos que as pessoas com deficiência tinham um único direito, que era o de estarem inseridos no mercado profissional, porém, não para serem reconhecidas como cidadãs, mas sim para suprirem a necessidade do sistema capitalista. Vemos, portanto, que nessa época ainda não existia uma acessibilidade adequada para as pessoas com deficiência, tampouco elas tinham uma possibilidade de qualificação, visto que as empresas do sistema capitalista recorriam a essas pessoas somente pelo aumento da mão-de-obra. 
Para que o objetivo desta pesquisa pudesse ser atingido, realizou-se uma revisão bibliográfica, com base em vários autores como Aranha (1995), Ethos (2002), Figueira (2008), Sassaki (2006), entre outros autores que foram importantes para este trabalho.

\section{METODOLOGIA}

Visando os objetivos desta pesquisa, que buscou tratar da inserção de pessoas com deficiência no mercado de trabalho, analisando a acessibilidade oferecida pelas empresas, de modo que a mesma permita a essas pessoas a obtenção de uma qualificação profissional, o presente estudo teve como fundamentação teórica leituras que contribuíram para analisar os desafios da inserção de deficientes no mercado de trabalho. Foram utilizados nove livros, duas revistas e oito artigos científicos em um período composto por três semestres letivos do curso de pós - graduação em Psicologia Organizacional e do Trabalho da Fundação Hermínio Ometto, no ano de 2018.

Trata-se de uma pesquisa exploratória, de natureza qualitativa, sendo caracterizado, segundo a natureza dos dados, como uma pesquisa bibliográfica, que se estruturou em três subitens onde:

- O primeiro subitem traz informações sobre a inserção da pessoa com deficiência no mercado de trabalho, bem como novos olhares trazidos pela nova constituição ao longo dos anos;

- O segundo subitem trata da acessibilidade que deve existir sobre essas pessoas, números que mostram sua quantidade no Brasil e a dificuldade na inserção das mesmas no mercado trabalhista;

- O terceiro subitem destaca a pessoa com deficiência e suas diversas colocações no mercado de trabalho.

Por fim, as considerações finais retomam sinteticamente as principais idéias apresentadas ao longo da pesquisa. 


\section{RESULTADOS E ANÁLISE}

Se na época monárquica não havia ainda a atenção e valorização necessárias, com a pessoa com deficiência trabalhando somente para suprir uma questão capitalista e não para ser reconhecida como de fato a deveria, no século $X X$, mudanças começaram a acontecer. Após a Segunda Guerra Mundial, veio a afirmação da cidadania completa, onde se percebeu a necessidade de valorizar a vontade da maioria, respeitando-se, sobretudo, às minorias, suas necessidades e peculiaridades.

Com a Constituição Federal de 1988, a pessoa com deficiência passa a ser olhada com ainda mais atenção. Esta constituição foi de suma importância no avanço, sendo referência de proteção por parte do Estado. Ela também deu à Assistência Social um status de Política Pública, que forma um tripé da Seguridade Social, formado também pela Previdência Social e pela Saúde.

Ao longo dos anos, percebeu-se que a pessoa com deficiência recebeu novos olhares a partir de novas leis e iniciativas governamentais. Porém, mesmo com a criação da Lei de Cotas, criada em 1991 e que concede direitos ao trabalhador com deficiência, proporcionando a cada empresa uma determinada quantidade de vagas para este empregado, conforme o número de funcionários que a mesma obtém, vemos que ainda falta acessibilidade de forma adequada para que essa lei funcione de fato, como deveria.

Ethos (2002) entende que a busca de ações para trazer a diversidade dentro das empresas é fundamental. Com essa busca, o objetivo seria a diminuição do preconceito e da desigualdade, tornando as instituições mais acessíveis e inclusivas a cada pessoa com deficiência.

Com base nessas ações, o desenvolvimento da cultura da pessoa com deficiência no mercado de trabalho torna-se imprescindível, a fim de ratificar a importância da implementação de um processo contínuo de aprendizagem dentro das empresas. 
Muitos lugares contratam pessoas com deficiência na busca de andarem dentro da lei. Porém, essas pessoas não possuem a oportunidade de crescimento, sendo colocadas somente em funções que não as permitem o mesmo. Desta forma, vemos que há uma inserção, mas não uma inclusão, que deveria, de fato, acontecer.

Dados do Censo Demográfico de 2010 colhidos através de uma pesquisa realizada pelo Instituto Brasileiro de Geografia e Estatística - IBGE mostram que 45,6 milhões de brasileiros, ou seja, 23,9\% da população declaram ter algum tipo de deficiência. $O$ censo foi realizado pesquisando deficiências visuais, auditivas, intelectuais e motoras, assim como seus graus de severidade.

Entre os entrevistados, a deficiência visual foi a que mais apareceu, com um número que representa 35,7 milhões de habitantes, dentre as quais mais de 6,5 milhões declararam ter a deficiência de forma severa, enquanto mais de 6 milhões disseram ter dificuldade de enxergar. Mais de 506 mil relataram serem cegas.

A deficiência que ficou em segundo lugar foi a motora, com mais de 13,2 milhões de pessoas afirmando terem algum grau do problema, equivalendo então a $7 \%$ dos brasileiros. Mais de 4,4 milhões de brasileiros declararam ter deficiência motora severa, dentre as quais mais de 734,4 mil disseram não conseguir caminhar ou subir escadas de forma alguma, enquanto mais de 3,6 milhões informaram ter grande dificuldade de locomoção.

Já a deficiência auditiva equivale a $5,1 \%$ da população, ou seja, 9,7 milhões de brasileiros, sendo que mais de 2,1 milhões de pessoas declararam terem a deficiência auditiva severa. 344,2 mil disseram ser surdas, enquanto 1,7 milhões de pessoas relataram ter grande dificuldade de ouvir. Por fim, mais de 2,6 milhões de brasileiros disseram ter deficiência intelectual.

Com o surgimento de novas leis, a pessoa com deficiência passou a ter mais direitos no que diz respeito à sua inclusão na sociedade e também no mercado de trabalho. Porém, podemos perceber que ainda existem muitas dificuldades para que a mesma ocorra de forma correta. 
Independentemente do tipo de deficiência e do grau de comprometimento apresentados pela pessoa com deficiência, isso não tira o direito de essa ser inclusa no mercado trabalhista. O que acontece é que a falta de informação e conhecimento dela a respeito de seus direitos garantidos por lei faz com que ainda existam na sociedade inúmeros casos de exclusão e discriminação.

Ainda de acordo com o Censo realizado pelo IBGE em 2010, podemos notar que poucas pessoas com deficiência possuem um grau de escolaridade elevado. $O$ Censo destaca que somente $6,7 \%$ da população brasileira com deficiência possui ensino superior completo, enquanto que $17,7 \%$ possuíam formação até o ensino médio e $14,2 \%$ até o ensino fundamental.

Quanto à alfabetização, o que se notou foi que as regiões Norte e Nordeste do Brasil são as com menores taxas de pessoas com deficiência alfabetizadas. Já as regiões Sudeste, Sul e Centro Oeste apresentaram as maiores taxas, com $88,2 \%, 88,1 \%$ e $84,6 \%$, respectivamente. A maior diferença entre taxas da população normal e da população com deficiência ocorreu no Nordeste, com 11,7 pontos percentuais. Esta diferença foi alta também na região Norte, com 8,8\%. A menor diferença apresentada foi na região Sul, com 6,9\%.

Com um número baixo de pessoas com deficiência academicamente formadas, a entrada na empresa acaba se tornando mais difícil, visto que o mercado de trabalho anda cada dia mais competitivo.

O Censo traz ainda informações sobre as pessoas com deficiência empregadas atualmente. Apesar da exigência legal de cotas para trabalhadores com deficiência, a participação deles no mercado trabalhista em 2010 ainda era baixa se comparada à das pessoas sem deficiência. Do total de 86,4 milhões de pessoas, de 10 anos ou mais, ocupadas, 20,4 milhões eram pessoas com deficiência, o que corresponde a $23,6 \%$ do total. Em 2010 havia 44.073 .377 pessoas com pelo menos uma deficiência em idade ativa, mas 23,7 milhões não estavam ocupadas. 
Uma sociedade inclusiva é aquela capaz de contemplar, sempre, todas as condições humanas, encontrando meios para que cada cidadão, do mais privilegiado ao mais comprometido, exerça o direito de contribuir com seu melhor talento para o bem comum (WERNECK, 2003, p. 12)

Segundo o autor, só viveremos em uma sociedade inclusiva quando esta, de fato, respeitar cada cidadão e suas diferenças, tendo em vista que cada um possui talentos em particular e que, independentemente de ser uma pessoa com deficiência, ainda assim pode usufruir desses talentos para uma melhor convivência de todos.

Segundo Sassaki (1997), "os problemas das pessoas com deficiência não estão tanto nelas tanto quanto estão na sociedade". Assim sendo, percebemos que também se faz necessário um olhar diferente da sociedade, que muitas vezes cria barreiras, impedindo que as pessoas com deficiência conquistem seu espaço como de fato deveriam tê-lo.

Bahia (2006) afirma que os problemas e barreiras existentes em relação às pessoas com deficiência são criados pela própria sociedade, que causa a essas pessoas desvantagens e incapacidades no desempenho de seus papeis sociais. Afirma ainda que essas barreiras são construídas por meio de políticas discriminatórias e preconceituosas, atitudes que acabam rejeitando as diferenças de cada minoria, bem como o desconhecimento de suas necessidades especiais e direitos que as pessoas com deficiência possuem, entre outras coisas. Segundo ele, essas barreiras tornamse ainda mais contundentes no mercado de trabalho.

"O princípio da inclusão se baseia na aceitação das diferenças individuais e na valorização do indivíduo, sabendo aceitar a diversidade, num processo de cooperação e conhecimento" (BAHIA, 2002).

Mediante o que foi visto até o presente momento, percebemos que a pessoa com deficiência ainda não é totalmente valorizada dentro do âmbito profissional, sendo que muitas também não possuem formações adequadas para determinadas atividades, sendo, desta forma, muitas vezes excluídas, não tendo a oportunidade de um 
emprego. Entretanto, ao conseguir essa oportunidade, a pessoa com deficiência pode ocupar várias colocações.

Em uma sociedade onde o mercado trabalhista é extremamente competitivo, a pessoa com deficiência pode ser inserida por três colocações diferentes dentro de um ambiente de trabalho. Há diversas maneiras de inserção que podem ser dar através de um autêntico contrato, até o serviço de forma autônoma.

O Decreto 3298/99, em seu artigo 35 destaca três modalidades de inserção no âmbito das empresas privadas, que são as colocações competitiva, seletiva e por conta própria.

A colocação competitiva é aquela na qual não se depende da adoção de procedimentos especiais para concretização, porém, não exclui a possibilidade do uso de apoios especiais que permitam compensar as restrições possuídas pela pessoa (art. 35, I, do Dec. n. 3298/99). Nesta colocação, o trabalho da pessoa com deficiência é um autêntico contrato de emprego dentro dos termos gerais dos artigos $2^{\circ}$ e $3^{\circ}$ da CLT.

$\mathrm{Na}$ colocação seletiva, há algumas diferenças em relação à colocação competitiva. Nesta colocação, a adoção de procedimentos especiais para a adoção se faz necessária. São considerados procedimentos especiais os meios utilizados para a contratação de pessoas que, devido a seu grau de deficiência, exijam condições especiais, tais como: jornada variável, horário flexível, proporcionalidade de salário, ambiente de trabalho adequado às suas especificidades, entre outras (art. $35, \S 2^{\circ}$, do Dec. 3298/99). A definição de procedimentos especiais também possui a mesma redação no artigo $5^{\circ}$ da Instrução Normativa n. 20/2001 do Ministério do Trabalho e Emprego. A definição de apoios especiais tem previsão nos artigos 35 , parágrafo $3^{\circ}$, do Decreto n. 3298/99 e $6^{\circ}$ da Instrução Normativa n. 20/2001 do Ministério do Trabalho e Emprego, que se referem à orientação e supervisão técnicas que auxiliem e tornem possível a compensação das limitações funcionais motoras, sensoriais ou mentais do portador de deficiência, de forma que possibilitem a ele a plena utilização de suas capacidades, em condição de normalidade. 
Já na colocação por conta própria, não há um vínculo empregatício e o trabalho fica a cargo da própria pessoa, que pode ser realizado de forma autônoma, cooperativa ou em regime de economia familiar, com vista à emancipação econômica e financeira (art. 35, I, do Dec. n. 3298/99).

Diante dessas três colocações, fica claro que a pessoa com deficiência possui totais condições de ser inserida no mercado de trabalho, podendo desta forma utilizar de suas capacidades para o crescimento da empresa e ser tratada semelhante a qualquer outro empregado.

\section{CONCLUSÃO}

Por muitos anos, a pessoa com deficiência não teve tanto espaço na sociedade. Com o passar do tempo, esse espaço foi aparecendo graças a criação de leis e decretos que favorecem a essa pessoa os mesmos direitos dos demais cidadãos da sociedade, dando a ela a oportunidade de ingressar na vida acadêmica e também de ter um emprego no qual ela possa se inserir e obter também sua chance de crescimento profissional, demonstrando suas habilidades dentro do ambiente no qual se insere.

De acordo com Laraia (2009), para que uma pessoa com deficiência possa ser autônoma e independente ao escolher e desenvolver seu trabalho e para que ela alcance e produza sua cidadania, devem ser-Ihe dados o direito à vida, à igualdade, ao trabalho, à reabilitação profissional, à habilitação, à saúde, à aposentadoria, ao lazer e à assistência especial, além do direito à não discriminação e à igualdade.

Borges e Longen (2007) dizem que a sociedade deve incentivar cada vez mais a inclusão de pessoas com deficiência no mercado trabalhista. Esse incentivo não deve se basear somente na lei, mas sim através de um olhar diferenciado para essas pessoas e também na transformação da cultura. Assim como o Estatuto e a Lei de Cotas, existem outras leis que asseguram o direito de pessoas com deficiência e são instrumentos fundamentais e importantes, mas é preciso assegurar que o foco nessas contratações deve ser não apenas quantitativo, mas sim qualitativo. 
A empresa precisa assegurar oportunidades iguais para todos os funcionários, conscientizando a todos das particularidades e dos direitos das PcDs, propiciando um ambiente saudável que incentivar os funcionários PcDs a crescer dentro da empresa como qualquer outro funcionário (GIMENES, et al, 2014)

Busca-se a cada ano uma sociedade mais justa e humana, sem discriminações e exclusões. Há diversas colocações para que a pessoa com deficiência possa se inserir no mercado trabalhista, mas mesmo com todas as leis e projetos, essa acessibilidade ainda é muito comprometida, visto que muitas empresas não estão oferecendo a estrutura e atenção necessárias para receber uma pessoa com deficiência em seu interior.

Em um país onde mais de $20 \%$ da população possui alguma deficiência, a exclusão não pode mais estar presente na sociedade e com os projetos e leis de favorecimento da inclusão, podemos perceber que cada pessoa, independentemente do tipo e grau de deficiência que possui, deve ser tratada de maneira igualitária, sobretudo no dia a dia de convivência com outras pessoas e no trabalho, onde ela merece também esse reconhecimento.

Assim sendo, cabe a nós continuarmos pesquisando sobre esse assunto tão presente nos dias atuais, buscando com cada aprendizado, contribuir para uma sociedade mais justa, onde cada pessoa com deficiência possa ter seu devido lugar e ser respeitada como os demais cidadãos, tendo um emprego e condições dignas de vida social.

\section{REFERÊNCIAS}

A inclusão da Pessoa com Deficiência no Mercado de Trabalho. Revista: Direitos Fundamentais e Democracia. Unibrasil. Curitiba. №2. Jul/2007

ALMEIDA, Lia Raquel Lima. Bioidentidades e Estratégias de Comunicação: A Deficiência Intelectual como foco de experiência em uma sociedade centrada na negociação de conhecimentos. Dissertação de Doutorado. Disponível em: 
https://tede2.pucsp.br/bitstream/handle/4689/1/Lia\%20Raquel\%20Lima\%20Almeida. pdf Acesso em 10/09/2018

ARANHA MSF. Integração social do deficiente: análise conceitual e metodológica. Temas Psicol. 1995; 2:63-70

AVAPE- Associação para Valorização de Pessoas com Deficiência. Dados sobre a associação. Disponível em: http://tecnologiasocial.fbb.org.br/tecnologiasocial/bancode-tecnologias-sociais/pesquisar-tecnologias/avape-associacao-para-valorizacao-depessoas-com-deficiencia.htm. Acesso em 06/07/2018

BAHIA, Melissa S. Responsabilidade Social e Diversidade nas Organizações: Contratando Pessoas com Deficiência. Rio de Janeiro: Qualitymark,2006.

BORGES, Aline Vieira; LONGEN, Willians Cassiano. A Acessibilidade nas Empresas: Percepções sobre a Inclusão de Pessoas com Deficiência no $\begin{array}{lllll}\text { Mercado de } & \text { Trabalho. } & \text { Disponível }\end{array}$ http://www.proceedings.blucher.com.br/article-details/a-acessibilidade-nasempresas-percepes-sobre-a-incluso-de-pessoas-com-deficincia-no-mercado-detrabalho-25812 Acesso em 11/07/2018

BRASIL. Decreto no 3298 de 20 de dezembro de 1999. Regulamenta a Lei n 7853 de 24 de outubro de 1989, que dispõe sobre a política Nacional para a integração da pessoa portadora de deficiência, consolida as normas de proteção e das outras providências.

BRASIL. Lei n 8213/91. Dispõe sobre os planos de Benefícios de previdência Social e das providências.

CARTILHA DO CENSO 2010 - Pessoas com Deficiência / Luiza Maria Borges Oliveira / Secretaria de Direitos Humanos da Presidência da República (SDH/PR) / Secretaria Nacional de Promoção dos Direitos da Pessoa com Deficiência (SNPD) / Coordenação-Geral do Sistema de Informações sobre a Pessoa com Deficiência; Brasília : SDH-PR/SNPD, 2012. Acesso em 01/06/2018. Disponível em 
http://www.pessoacomdeficiencia.gov.br/app/sites/default/files/publicacoes/cartilhacenso-2010-pessoas-com-deficienciareduzido.pdf

DINIZ, Debora; BARBOSA, Lívia; SANTOS, Wederson Rufino dos. Deficiência, Direitos Humanos e Justiça.Sur, Rev. Int. Direitos Humanos. Vol.6, n.11, São Paulo, Dec./2009. Acesso em 25/05/2018. Disponível em: http://www.scielo.br/scielo.php?pid=S180664452009000200004\&script=sci_abstract \&tlng $=p t$.

ETHOS. O que as empresas podem fazer pela inclusão das pessoas com deficiência/ coordenação Marta Gil- São Paulo: Instituto Ethos, 2002

FIGUEIRA, Emílio. Caminhando em silêncio: uma introdução à trajetória das pessoas com deficiência na história do Brasil. São Paulo: Giz Editorial, 2008.

FREITAS, Maria Nivalda de Carvalho. A Diversidade através da História: A Inserção no trabalho de Pessoas com Deficiência. Disponível em: http://www.scielo.br/pdf/osoc/v14n41/03.pdf. Acesso em: 30/05/2018

GIMENES, Antonia Maria, et al. A Dificuldade da Inclusão da Pessoa com Deficiência no Mercado de Trabalho. Disponível em : https://www.inesul.edu.br/revista/arquivos/arq-idvol_33_1426199840.pdf Acesso em 27/07/2018.

LARAIA, Maria Ivone Fortunato. A Pessoa com deficiência e o direito ao trabalho. Dissertação de mestrado. Disponível em: https://tede.pucsp.br/bitstream/handle/.../1/Maria\%20lvone\%20Fortunato\%20Laraia. pdfAcesso em: 03/08/2018

SASSAKI, Romeu Kazumi. Inclusão : Construindo uma sociedade para todos - $7^{\text {a }}$ Edição. Rio de Janeiro: WVA,2006. 
. Vida independente: historia, movimento, liderança, conceito, reabilitação, emprego e terminologia. São Paulo/SP. Revista nacional de reabilitação. 2003.

Inclusão: Construindo uma sociedade para todos. Rio de Janeiro: WVA, 1997.

SILVA, Luzia Félix da. A INCLUSÃo DA PESSOA COM DEFICIÊNCIA NO MERCADO DE TRABALHO: Desafios e Superações no Ambiente de Trabalho. Trabalho de Conclusão de Curso do Serviço Social: Universidade Estácio de Sá, 2015, 59 p. Disponível em : https://monografias.brasilescola.uol.com.br/administracaofinancas/a-inclusao-pessoa-com-deficiencia-no-mercado-trabalho.htm. Acesso em 07/07/2018

WERNECK, Claudia. Você é Gente? Rio de Janeiro: WVA,2003.

Enviado: Setembro, 2019.

Aprovado: Junho, 2020. 